\title{
Flexible endoscopy with noninvasive ventilation assesses and manages infants with severe bronchopulmonary dysplasia
}

\author{
Wen-Jue Soong ${ }^{1}$, Pei-Chen Tsao ${ }^{2}$, Chia-Feng Yang ${ }^{3}$, Yu-Sheng Lee ${ }^{2}$, Chieh-Ho Chen ${ }^{4}$, \\ Chien-Heng Lin ${ }^{5}$, and Yi-Hung Sung $^{2}$ \\ ${ }^{1}$ Children's Hospital, China Medical University \\ ${ }^{2}$ Taipei Veterans General Hospital \\ ${ }^{3}$ Taipei veterans general hospital \\ ${ }^{4}$ China Medical University \\ ${ }^{5}$ China Medical University Hospital
}

September 24, 2021

\begin{abstract}
Objectives Flexible endoscopy (FE) assessed the whole approachable aeroesophageal (AE) tracks and changes of management in infants with severe bronchopulmonary dysplasia (sBPD). Methods A 10 years (2011-2020) retrospective study of sBPD infants who had FE with and without artificial airway in AE tracks. FE with noninvasive ventilation (FE-NIV) of pharyngeal oxygen with nose-close and abdomen-compression was supported. Data of found pathologies, changes of consequent management and therapeutic interventions were collected and analyzed. Results Total 42 infants enrolled. Two scopes of $1.8 \mathrm{~mm}$ and $2.6 \mathrm{~mm}$ were used. FE revealed 129 AE pathologies in 38 (90.5\%) infants. Twenty-eight (66.7\%) infants detected more than one lesion. In 35 (83.3\%) infants with 111 airway lesions, bronchial granulations (28, 25.2\%), tracheomalacia (18, 16.2\%) and bronchial granulations $(15,13.5 \%)$ were the leadings. Fifteen $(35.7 \%)$ infants had 18 esophageal lesions. No significant FE-NIV complication noted. FE findings resulted consequent changes of management in all 38 infants. Thirty-six (85.7\%) infants involved respiratory care of pressure titrations $(29,45.3 \%)$, shorten suctioning depth $(17,26.6 \%)$, changed endotracheal or tracheostomy tube depth $(10,15.6 \%)$ and extubation $(8,12.5 \%)$. Twenty-one (50\%) infants had 50 medication changes included add steroids, anti-reflux medicine, antibiotics and stop antibiotics. Eighteen (42.8\%) infants had received 37 therapeutic FENIV procedures which included 14 balloon dilatation, 13 laser-plasty and 10 stent implantations. Seven (16.7\%) infants had surgeries included 4 tracheostomies and 3 fundoplications. Conclusion FE-NIV can be a safe and valuable modality for direct visual assessment of $\mathrm{AE}$ pathologies which contributed subsequent changes of clinical management in sBPD infants.
\end{abstract}

Title pages

Flexible endoscopy with noninvasive ventilation assesses and manages infants with severe bronchopulmonary dysplasia

Wen-Jue Soong ${ }^{1,2,3}$, Pei-Chen Tsao ${ }^{2,4}$, Chia-Fang Yang ${ }^{2,4}$, Yu-Sheng Lee ${ }^{2,4}$, Chien-Heng Lin ${ }^{1}$, Chieh-Ho Chen ${ }^{1}$, Yi-Hung Sung ${ }^{5}$

${ }^{1}$ Division of Pediatric Pulmonology, Children's Hospital, China Medical University, Taichung, Taiwan;

${ }^{2}$ Department of Pediatrics, Taipei Veterans General Hospital, Taipei, Taiwan;

${ }^{3}$ Department of Pediatrics, Tri-Service General Hospital, National Defense Medical Center, Taipei, Taiwan;

${ }^{4}$ Department of Pediatrics, School of Medicine, National Yang-Ming Chiao Tung University; Taipei, Taiwan; 
${ }^{5}$ Department of Medical Education, MacKay Memorial Hospital, Taipei, Taiwan

Abbreviated title: Bronchoscopy effects in severe BPD infants

Key words : Bronchopulmonary dysplasia, flexible bronchoscopy, premature infant, noninvasive ventilation, Soong's ventilation

Corresponding author:

\section{Wen-Jue Soong, MD}

Division of Pediatric Pulmonology, China Medical University Children's Hospital, Taichung, Taiwan.

No. 2, Yuh-Der Road, Taichung 40447, Taiwan.

Phone: +886-4-22052121 ext. 4648;

Fax.: +886-4-22032798;

Cell phone: +886-921067989;

E-mail: wjsoong3@gmail.com

\section{Financial disclosure:}

- This study was approved by Ethical committee review board of Taipei Veterans General Hospital (IRBTPEVGH No.:2021-08-015BC).

- There is no support from any manufacture or company about this study.

- The first author, Wen-Jue Soong, wrote the first draft of the manuscript.

- Report to Pediatric Pulmonology: on behalf of all authors, the corresponding author states that there is no conflict of interest with any person or company.

\section{Authorship list}




\begin{tabular}{|c|c|c|c|c|}
\hline Name & $\begin{array}{l}\text { Highest } \\
\text { academic } \\
\text { degree }\end{array}$ & E-mail & $\begin{array}{l}\text { Contribution } \\
\text { statement }\end{array}$ & Affiliations \\
\hline $\begin{array}{l}\text { Wen-Jue } \\
\text { Soong }\end{array}$ & MD & $\begin{array}{l}\text { wjsoong3@gmail.com } \\
\text { Orcid id: 0000- } \\
\text { 0002-8397-4956 }\end{array}$ & $\begin{array}{l}\text { Conceptualization, } \\
\text { Methodology, } \\
\text { Investigation, } \\
\text { Resources, } \\
\text { Writing-original } \\
\text { draft, } \\
\text { Supervision... }\end{array}$ & $\begin{array}{l}{ }^{1} \text { Division of } \\
\text { Pediatric } \\
\text { Pulmonology, } \\
\text { Children's Hospital, } \\
\text { China Medical } \\
\text { University, } \\
\text { Taichung, Taiwan; } \\
{ }^{2} \text { Department of } \\
\text { Pediatrics, Taipei } \\
\text { Veterans General } \\
\text { Hospital, Taipei, } \\
\text { Taiwan; } \\
{ }^{3} \text { Department of } \\
\text { Pediatrics, } \\
\text { Tri-Service General } \\
\text { Hospital, National } \\
\text { Defense Medical } \\
\text { Center, Taipei, } \\
\text { Taiwan; }{ }^{4} \text { School of } \\
\text { Medicine, National } \\
\text { Yang-Ming } \\
\text { University; Taipei, } \\
\text { Taiwan; } \\
{ }^{5} \text { Department of } \\
\text { Medical Education, } \\
\text { MacKay Memorial } \\
\text { Hospital, Taipei, } \\
\text { Taiwan; }\end{array}$ \\
\hline Pei-Chen Tsao ${ }^{2,4}$ & MD, PHD & $\begin{array}{l}\text { tsao3840@gmail.com } \\
\text { Orcid id: } \\
\text { 0000-0003-1613-653 }\end{array}$ & $\begin{array}{l}\text { Investigation, } \\
\text { Project } \\
\text { administration. . }\end{array}$ & \\
\hline Chia-Feng Yang ${ }^{2,4}$ & $\mathrm{MD}, \mathrm{PhD}$ & $\begin{array}{l}\text { Cfyang3@vghtpe.gov.t } \\
\text { Orcid id: 0000- } \\
\text { 0001-5739-5216 }\end{array}$ & $\begin{array}{l}\text { wnvestigation, } \\
\text { Project } \\
\text { administration. . }\end{array}$ & \\
\hline Yu-Sheng Lee ${ }^{2,4}$ & $\mathrm{PhD}$ & $\begin{array}{l}\text { leeys@vghtpe.gov.tw } \\
\text { Orcid id: 0000- } \\
\text { 0003-0438-0082 }\end{array}$ & $\begin{array}{l}\text { Investigation, } \\
\text { Project } \\
\text { administration. . . }\end{array}$ & \\
\hline Chien-Heng Lin ${ }^{1}$ & $\mathrm{MD}$ & $\begin{array}{l}\text { Lch227@ms39.hinet.r } \\
\text { Orcid id: 0000- } \\
\text { 0002-9278-5911 }\end{array}$ & $\begin{array}{l}\text { Anvestigation, } \\
\text { Project } \\
\text { administration... }\end{array}$ & \\
\hline Chieh-Ho Chen ${ }^{1}$ & MD & $\begin{array}{l}\text { pedlungcmu@gmail.cc } \\
\text { Orcid id: 0000- } \\
\text { 0003-4486-7464 }\end{array}$ & $\begin{array}{l}\text { nInvestigation, } \\
\text { Writing-review \& } \\
\text { editing }\end{array}$ & \\
\hline Yi-Hung Sung ${ }^{5}$ & $\mathrm{MD}$ & $\begin{array}{l}\text { yheddysung@gmail.co } \\
\text { Orcid id: 0000- } \\
\text { 0002-8423-5223 }\end{array}$ & $\begin{array}{l}n \text { Writing-review \& } \\
\text { editing }\end{array}$ & \\
\hline
\end{tabular}




\section{Flexible endoscopy with noninvasive ventilation assesses and manages infants with severe bron-}

chopulmonary dysplasia

\section{Background}

Successful management of severe bronchopulmonary dysplasia (sBPD) requires a multidisciplinary approach to optimize respiratory care, proper pharmacotherapy, adequate nutrition, offer appropriate interventions and search for comorbidities. Much importance is placed on identifying the pathologies in each infant with sBPD and accordingly adjust their individualized managing strategies in an evidence-based fashion. Flexible endoscopy (FE) is a well-established and safe tool for direct visual inspection and evaluation of dynamic aero-esophageal (AE) anomalies for patients in the endoscopy room or intensive care unit (ICU) setting. ${ }^{1-3}$ Infants with sBPD typically have prolonged hospitalization course requiring numerous invasive managing in the AE tract which include invasive positive pressure ventilation (PPV), multiple attempts of intubation and extubation of endotracheal tube (ET) and feeding tube, noninvasive ventilation (NIV) and airway suctioning during hospitalization. ${ }^{4,5}$ As result, they are vulnerable and risky for iatrogenic AE lesions such as subglottic stenosis, tracheomalacia (TM), bronchomalacia $(\mathrm{BM})^{6-8}$ and gastroesophageal reflux disease (GERD) ${ }^{9-11}$ Studies reported that only less than $5 \%$ of patients with BPD had normal airway evaluations. ${ }^{12}$ Thus, it is important to perform a detailed $\mathrm{FE}$ of $\mathrm{AE}$ tract so that pathologies can be fully identified. However, the existed $\mathrm{AE}$ anomalies and associated cardiopulmonary dysfunction remain challenging for performing the invasive FE procedures and consequent FE-related interventions.

"Pharyngeal oxygen with optional nose-closure and abdomen-compression ( $\left.\mathrm{PhO}_{2}-\mathrm{NC}-\mathrm{AC}\right)$ " is a novel model of NIV with advantages of providing PPV without using artificial device such as Ambu-bag, face or nasal mask, laryngeal mask airway, ET or mechanical ventilator. Previous studies have demonstrated its efficacy in providing adequate oxygenation and ventilation during $\mathrm{FE}$ assessment of entire AE tract in pediatric patients with risk of hypoxemia or even respiratory failure. ${ }^{13-17}$ To our knowledge, there is no study dealing the modality of FE with this NIV (FE-NIV) support to evaluate infants with sBPD.

The primary objectives of this study were 1) to describe the diagnostic findings of FE-NIV for assessment of $\mathrm{AE}$ lumens and 2) the resultant changes in clinical management of infants with sBPD.

\section{Methods}

This was a 10-years retrospective review of infants with sBPD at a tertiary and transferred medical center, Taipei Veterans General Hospital in Taiwan, who underwent FE from January 2011 to December 2020. Only FE performed after made sBPD diagnosis during the hospitalization were included for this analysis. Written informed consent was obtained from parents/legal guardians before the FE procedure. Ethical committee review board of hospital approved this study (IRB-TPEVGH No.:2021-08-015BC).

\section{Patient enrolled}

Patients were diagnosed with sBPD if they met the following criterias ${ }^{7}$ described by National Institute of Child Health and Development (NICHD). An infants is diagnosed with sBPD if 1) born prior to 32 weeks postmenstrual age (PMA) and required supplemental oxygen for [?]28 days and [?]30\% oxygen concentration or PPV at 36 weeks PMA, 2) born after 32 weeks gestational age and prior to 37 weeks gestational age who required supplemental oxygen for [?]28 days and [?]30\% oxygen concentration or PPV at 56 days of life. As the use high flow nasal cannula (HFNC) was not specified, infants born prior to 32 weeks PMA or born after 32 weeks but prior to 37 weeks PMA were defined as having sBPD if on $>2$ LPM with any inspired oxygen at 36 weeks PMA or 56 days of life respectively. Failure of extubation was defined by a need for re-intubation within 48 hours of extubation. Infants with congenital cardiovascular disease were excluded from this study.

Patient preparation

All FE's were performed at bedside of neonatal intensive care unit (ICU) or Pediatric ICU. Procedural sedation was administered with intravenous midazolam $(0.1-0.2 \mathrm{mg} / \mathrm{kg})$ with or without ketamine $(1-2 \mathrm{mg} / \mathrm{kg})$ while maintaining spontaneous breathing. Topical anesthesia of $2 \%$ lidocaine solution $(1-2 \mathrm{ml} / \mathrm{kg})$ was applied 
via ET into distal airways. For infants without ET or just extubation, the lidocaine solution was applied into nostrils, larynx and tracheal lumen with a syringe catheter (a trimmed suction catheter attached to a 5 -ml syringe) under rigid laryngoscopy. Continuous vital signs, including non-invasive blood pressure every 5 minutes, were monitored throughout the FE-NIV procedure.

NIV support

Infant's original respiratory devices including nasal cannula, nasal prongs, artificial airway and mechanical ventilator, if presented, were replaced with the following NIV support. The tracheostomy stoma, if presented, was sealed closely sealed with tape.

NIV support using $\mathrm{PhO}_{2}$-NC-AC approach ${ }^{13,15}$ throughout the whole FE course which was described below. A continuous, warmed and humidified pure oxygen flow $(1.0 \mathrm{~L} / \mathrm{kg} / \mathrm{min})$ was delivered through a nasopharyngeal catheter (preferably right nostril) to fill the upper airway cavity. In this NIV, sustained pharyngeal inflation (SPI) with duration of nose-closure (NC) of 0 to 3 seconds was optionally applied. With infant's mouth closed by hooking endoscopist's right index finger at submental bone, following maneuvers were performed to deliver the PPV: (1) Inspiration phase was accomplished by NC with thumb and mid-finger (Figure 1a). Cricoid pressure might also be applied concurrently with endoscopist's ipsilateral little finger. SPI was performed for 0 to 3 seconds. (2) Expiration phase (Figure 1b) was started passively with the release of $\mathrm{NC}$ and cricoid pressure, which could be facilitated with simultaneous abdomen-compression (AC) over umbilical region. Above steps were performed optionally at a rate of 5-10 cycles per minute. Endoscopist could simultaneously doing both the FE and NC (release) maneuver, while an assistant (if present) might give the $\mathrm{AC}$ (release).

Flexible endoscopy

FE-NIV performed in the following routes.

1. For infants with invasive airways (ET or tracheostomy tube), FE proceeded directly via the invasive airway checking lumens inside and beyond the tip. Then, extubated and did FE again as below.

2. For infants without invasive airway (or after extubation), FE was performed via the nostril (left) and examined down to all-approachable distal bronchial lumens.

3. Finally, the scope withdrew back to pharynx, re-cannulated and assessed the esophagus and stomach.

After FE-NIV assessment, infants remained in the ICU care for consequent clinical management.

Data abstraction and analysis

Infants' characteristics and information were collected from the electronic medical records. Gross findings of the AE tract and associated complications were obtained from the FE reports. Airway malacia was diagnosed when there was greater or equal to $50 \%$ reduction in the luminal diameter during spontaneous breathing. Categorical variables are reported as frequency and percentage, while continuous variables are reported with median and interquartile range. All data analyses were performed using Stata 13.1 software.

\section{Results}

A total of 42 infants were enrolled (Table 1). Thirty-two (76.2\%) infants were transferred from other medical centers. The mean gestational age at birth was 27.1 weeks. At the time of FE, infants had median PMA of 43.2 weeks, median chronological age of 15.1 weeks, and mean (SD) body weight of $3.4(0.6) \mathrm{kg}$. Of the $22 / 42(52.4 \%)$ infants who required respiratory supports with invasive airway, $15 / 42(35.7 \%)$ had ETs and $5 / 42(11.9 \%)$ had tracheostomy tubes; PPV with nasal prongs was used in 16/42 (38.1\%) infants and oxygen cannula was used in $4(9.5 \%)$ infants. The leading indications for FE assessment were failure to wean PPV in $36(85.7 \%)$, failed ET extubation in $27(64.3 \%)$ and abnormal breathing sound in $15(35.7 \%)$. Thirty-five $(83.3 \%)$ infants had more than one indication.

Endoscopes used 
Two thin flexible endoscopies without inner channel, Olympus LFP scope (out diameter $1.8 \mathrm{~mm}$, working length $60 \mathrm{~cm}$ ) or Olympus LFP scope (out diameter $2.6 \mathrm{~mm}$, working length $30 \mathrm{~cm}$ ), were used for FE-NIV procedures. Endoscopes of appropriate size were chosen to pass and assess through $2.5 \mathrm{~mm}$ to $4.0 \mathrm{~mm}$ inner diameters of invasive airway as well as from the nose to all approachable AE tract in infants without invasive airway.

FE revealed AE tracts pathologies in 38 (90.5\%) infants where total of 129 lesions were identified (Table 2). There included 111 airway lesions in 35 (83.3\%) infants and 18 esophageal problems in $15(35.7 \%)$ infants. Among them, $28(66.7 \%)$ infants had detected more than one lesion. Of the 111 airway lesions, most frequently identified were bronchial granulations (28, 25.2\%), TMs (18, 16.2\%), BMs (15, 13.5\%) and subglottic stenoses (11, 9.9\%). Bronchial granulations were right side dominant (right 21, left 10 and bilateral 7 ), and all at distal bifurcations of the primary bronchi, contributing to local malacia. The 18 esophageal lesions identified comprised of $12(66.7 \%)$ loose of gastroesophageal junction, 3 (16.7\%) esophageal inlet stenoses and $3(16.7 \%)$ mid-esophageal stenoses.

The mean (SD) duration of FE-NIV procedure for infant with invasive airway was 102 (33) seconds, whereas for infants without airway tubing, assessing whole three routes of AE tract was 227 (55) seconds. (Table 3) Eight (19\%) infants had developed transient desaturation ( $<85 \%$ or less than $10 \%$ of prior baseline level) or bradycardia $(<100$ beat/min) more than than 60 seconds. They all got recovery within 60 seconds after a brief NIV (NC-AC) maneuvers. Durations of desaturation or bradycardia were all less than 120 seconds. No pulmonary air-leak associated with the FE-NIV procedures was noted. All infants successfully withstood and completed the FE-NIV procedures.

FE findings led to resultant changes in clinical management in 38/42 (90.5\%) infants (Table 4), where a total of 158 changes along with the respective rationales was tallied. There were 64 changes of respiratory care among 36/42 (85.7\%) infants, which consisted of titrations of PPV (29/64, 45.3\%), shallow suctioning (17/64, $26.6 \%)$, ET (or tracheostomy tube) insertion depth adjustments $(10 / 64,15.6 \%)$ and ET extubations $(8 / 64$, $12.5 \%)$. Twenty-one $(21 / 42,50.0 \%)$ infants had changed 50 medications which included addition of systemic steroids $(15 / 50,30.0 \%)$, addition of anti-reflux medicine $(14 / 50,28.0 \%)$, discontinuation of antibiotics $(13 / 50$, $26.0 \%)$, and addition of antibiotics (8/50,16.0\%). In 18 (42.9\%) infants, 37 therapeutic interventions were performed with the aid of FE-NIV, which included balloon dilatations of narrow lumens (14/37, 37.8\%), laser-plasty for stenotic lesions or granulation ablations $(13 / 37,35.1 \%)$ and stents implantation $(10 / 37$, $27.0 \%$ ) for severe (collapse more than 90\%) tracheobronchial malacia caused difficult weaning the PPV. In these 10 stents implantations, there were 4 TM, 4 CM (2 right and 2 left) and 2 left main BM. Seven $(7 / 42,16.7 \%)$ infants received surgical procedures due to failure of medical management which included 4 tracheostomies for severe subglottic stenosis and 3 fundoplications for severe GERD.

\section{Discussion}

This is the first report in literature on performing FE-NIV assessment in the whole approachable AE tract in infants with sBPD. FE-NIV is a practical and well-tolerated modality even in cardiopulmonary compromised infants. In this study, all infants received complete FE assessments, and each assessment was safely accomplished in no more than seven minutes. Transient desaturation or bradycardia that occurred were all resolved in less than two minutes of applying this NIV maneuvers.

BPD is a clinically challenging condition. Many AE tract pathologies that resulted in lumen narrowing or incompetency may be frequently undiagnosed or misdiagnosed due to poor diagnostic value of indirect radiographic images or intolerance to direct FE procedures without appropriate support. Airway tissue of premature infants are particularly vulnerable be injury as they are fragile and compliant. ${ }^{19,20}$ Since birth, their AE tracts bore frequent invasive processes such as intubations, suctioning, infections and barotrauma of prolonged PPV during their complicated and lengthy hospitalizations. These iatrogenic damages might result in tissue fibrosis, lumen stenosis and structural weakness. ${ }^{21-23}$ In addition, infants with sBPD also encounter recurrent complications such as sepsis, cyanotic episodes, apnea and difficulty weaning. Therefore, they are best assessed and managed by a multidisciplinary team specializing in comprehensive care of the complex 
disorders.

For infants with invasive airways (ET or tracheostomy tube), we started the FE assessment through the artificial lumens evaluating tissue-condition around the tube's tip, where the most iatrogenic trauma rise. By manipulating FE and invasive airway, we imitate the dynamic ET tip motion and the suction catheter against the mucosal wall of tracheobronchial lumens in vivo. The ET or FE tips might embed into a granuloma, against the main carina, or even block a bronchial branch. Additionally, the tip of suction catheter might repeatedly striking against the bifurcations of a branch and resulted in granulation formations. All of these causes of traumatic striking might be ignored after extubation. For infants without ET or after extubation, comprehensive assessment with FE-NIV began from the nostrils down to the all-approachable bronchi, esophagus, and stomach were performed with increased focus around the hypopharynx, larynx and supra-stomy region where majority of ET, tracheostomy tube, suctioning and feeding tube related injuries might exist. ${ }^{24-26}$ Kurachek, et al. ${ }^{22}$ reported that that upper airway lesions like laryngomalacia, subglottic stenosis, TM, BM or tracheobronchial malacia are the leading causes of extubation failure in pediatric patients. In this study, majority of infants with sBPD $(38 / 42,90.5 \%)$ had AE pathologies detected by FE-NIV. These findings highlight the importance of performing precise AE tracts evaluation.

Failure of extubation or weaning respiratory support in patients with sBPD due to pathologies involving AE tract have been well reported in the literature. ${ }^{23,27-29}$ In our study, positive rate of $90.5 \%(38 / 42)$ was higher than rate of $74.0 \%$ (20/27) from previous study by Hysinger ${ }^{4}$ in which only airway pathologies were identified. Utilizing the novel FE-NIV approach, we were safely take time and able to detailedly examined AE regions including pharyngolarynx, upper trachea and esophagus, and thus, yielded more pathologic findings. These findings allowed us to further adjust and formulate appropriate and individualized treatment strategies for lesions encompassing not only the airway tracts, but also the esophageal portions.

Consequent changes of respiratory cares and medication management were adjustment. For symptomatic or refractory airway lesions such as severe granulations, stenosis and malacia, we were capable of providing effective therapeutic interventions through the FE-NIV procedure, ${ }^{15,30}$ including laser ablation for granulations and balloon dilatation for lumen stenoses. Additionally, in selected infants of severe airway malacia with frequent life-threatening episodes and failed to achieve satisfactory response to such management, we were able to performed stent placements ${ }^{16,30}$ over the affected sites with aid of FE-NIV, thus forestalling the need of more invasive surgical approach. In this study, surgeries of tracheostomy and gastric fundoplication were reserved for severe, refractory subglottic stenosis and GERD, respectively.

Performing FE-NIV approach for assessment of sBPD infants provides several advantages. First, it is a simple and practical skill that obviates the need for artificial airway devices such as face-mask, ventilation bag, laryngeal airway mask, ET, ventilator, or equipment as HFNC that is cost-effective and applicable in resource-limited situations. Compare to the HFNC, this NIV may be better in less oxygen flow needed, interface near the larynx, and provide controllable PPV for effects of splinting airway and oxygenation. Second, in the " $\mathrm{PhO}_{2}$ ", the ventilation interface locates near the larynx which has less death space and it functioning likes the physiology of "apneic oxygenation" 31,32 can prolong duration of safe oxygen saturation. Third, due to less airway devices used, workspace for FE handling and manipulation is less occluded, allowing for smoother procedure, careful measurement and yield more comprehensive pathologies. Fourth, it can provide direct and dynamic visual evidence-base information that is valuable to formulate clinical decisions for individualized management. Fifth, addition of SPI and AC, it can safely support the PPV, provide a less hurried approach, improve the FE assessment as well as the more invasive therapeutic procedures, even in cardiopulmonary compromised infants. ${ }^{15-17,29}$

There are several limitations presented in this study. 1) Due to retrospective nature, it was difficult to clarify the complex factors contributed to these pathologies, especially for infants who were transferred to our hospital relatively late in their clinical courses. 2) No bronchoalveolar lavage was performed during FE that was due to it could easily be achieved by direct suction from invasive airway and also concerned about tracheobronchial colonization in these infants. As result, we preferred using FE with no inner channel. 3) The sample size was small and the FE-NIV used in the study was single-center based. Future multicenter 
studies of the FE-NIV assessment in whole AE tract may be needed to more clarify the issues.

\section{Conclusion}

This FE-NIV is a simple, safe and valuable procedure for obtaining direct visuals and complete diagnosis of $\mathrm{AE}$ lesions, which could assist clinicians in formulating appropriate clinical decisions to guide individualized management in infants with sBPD.

\section{Conflict of Interests}

All authors declare that there is no conflict of interests regarding this paper.

\section{References}

1. Peng YY, Soong WJ, Lee YS, Tsao PC, Yang CF, Jeng MJ. Flexible bronchoscopy as a valuable diagnostic and therapeutic tool in pediatric intensive care patients: a report on 5 years of experience. Pediatr Pulmonol. 2011;46:1031-1037. doi:10.1002/ppul.21464. Epub 2011 May 27.

2. DeBoer EM, Prager JD, Kerby GS, Stillwell PC. Measuring pediatric bronchoscopy outcomes using an electronic medical record. Ann Am Thorac Soc. 2016;13:678-683.

3. Soong WJ, Tsao PC, Lee YS, Yang CF. Therapeutic flexible airway endoscopy of small children in a tertiary referral center-11 years' experience. PLoS ONE 2017:12(8): e0183078. https://doi.org/10.1371/journal.pone.0183078

4. Hysinger EB, Friedman NL, Padula MA, Shinohara RT, Zhang H, Panitch HB, et al. Tracheobronchomalacia is associated with increased morbidity in bronchopulmonary dysplasia. Ann Am Thorac Soc 2017; 14:1428-1435.

5. Jensen EA, DeMauro SB, Kornhauser M, Aghai ZH, Greenspan JS, Dysart KC. Effects of multiple ventilation courses and duration of mechanical ventilation on respiratory outcomes in extremely lowbirth-weight infants. JAMA Pediatr. 2015;169:1011-1017.

6. Sant'Anna GM, Keszler M. Weaning infants from mechanical ventilation. Clin Perinatol. 2012;39:543562.

7. Ehrenkranz RA, Walsh MC, Vohr B0R, Jobe AH, Wright LL, Fanaroff AA, et al. Validation of the national institutes of health consensus definition of bronchopulmonary dysplasia. Pediatrics. 2005;116:1353-1360.

8. Downing GJ, Kilbride HW. Evaluation of airway complications in high-risk preterm infants: application of flexible fiberoptic airway endoscopy. Pediatrics. 1995;95:567-572.

9. Nobile S, Noviello C, Cobellis G, Carnielli VP. Are infants with bronchopulmonary dysplasia prone to gastroesophageal reflux? A prospective observational study with esophageal pH-Impedance monitoring. J Pediatr 2015;167:279-285.

10. Eric C. Eichenwald EC. Diagnosis and Management of Gastroesophageal Reflux in Preterm Infants. Pediatrics 2018; 142 (1) e20181061; DOI: https://doi.org/10.1542/peds.2018-1061.

11. Wang LJ, Hu Y, Wang W, Zhang CY, Yu Z, Bai YZ, Shu-Cheng Zhang SC, Gastroesophageal reflux poses a potential risk for late complications of bronchopulmonary dysplasia: a prospective cohort study. doi.org/10.1016/j.chest.2020.05.523

12. Cohn RC, Kercsmar C, Dearborn D. Safety and efficacy of flexible endoscopy in children with bronchopulmonary dysplasia. Am J Dis Child. 1988;142:1225-1228.

13. Soong WJ, Jeng MJ, Lee YS, Tsao PC, Harloff M, Matthew Soong YH. A novel technique of noninvasive ventilation: Pharyngeal oxygen with nose-closure and abdominal-compression- Aid for pediatric flexible bronchoscopy. Pediatr Pulmonol. 2015;50:568-575.

14. Soong WJ, Yang CF, Lee YS, Tso PJ, Lin CH, Chen CH. Vallecular cyst with coexisting laryngomalacia: successful diagnosis and laser therapy by flexible endoscopy with a novel noninvasive ventilation support in infants. Ped Pulmonol 2020:1-7. DOI: 10.1002/ppul.24796

15. Soong WJ, Pediatric Interventional Flexible Bronchoscopy. Pediatr Respiro Crit Care Med. 2018; 2: 38-44. http://www.prccm.org on Monday, October 29, 2018, IP: 203.64.247.4

16. Soong WJ, Tsao PC, Lee YS, Yang CF. Flexible endoscopy for pediatric tracheobronchial metal- 
lic stent placement, maintenance and long-term outcomes. PLoS ONE 2018:13: e0192557. https://doi.org/10.1371/journal. pone.0192557

17. Soong WJ, Lee YS, Tsao PC, Yang CF. Retrieval of Tracheobronchial foreign bodies by short flexible endoscopy in children. Int J Pediatr Otorhinolaryngol. 2017:95;109-113.

18. Soong WJ, Chen CH, Lin CH, Yang CF, Lee YS, Tsao PJ, Sung YH, Dhochak N. Sustained pharyngeal inflation on upper airway effects in children - flexible bronchoscopy measurement. Pediatr Pulmonol 2021; (in print)

19. Shaffer TH, Bhutani VK, Wolfson MR, Penn RB, Tran NN. In vivo mechanical properties of the developing airway. Pediatr Res 1989;25:143-146.

20. Islam JY, Keller RL, Aschner JL, Hartert TV, Moore PE. Understanding the short- and long-term respiratory outcomes of prematurity and bronchopulmonary dysplasia. Am J Respir Crit Care Med $2015 ; 192: 134-156$.

21. Holzki J, Laschat M, Puder C. Iatrogenic damage to the pediatric airway: mechanisms and scar development. Pediatric Anesthesia 200919 (Suppl. 1):131-146.

22. Kurachek SC, Newth CJ, Quasney MW, Rice T, Sachdeva RC, Patel NR, et al. Extubation failure in pediatric intensive care: A multiple-center study of risk factors and outcomes. Crit Care Med. 2003;31:2657-2664.

23. Hysinger EB. Central airway issues in bronchopulmonary dysplasia. Ped Pulmonol 2021:1-9 DOI: 10.1002/ppul.25417

24. Lambercy K, Pincet L, Sandu K. Intubation Related Laryngeal Injuries in Pediatric Population. Front. Pediatr., 10 February 2021 | https://doi.org/10.3389/fped.2021.594832

25. Soong W.J. Endoscopic diagnosis and management of iatrogenic cervical esophageal perforation in extremely premature infants. J Chin Med Assoc. 2007; 70: 171-175

26. BH Su, HY Lin, HY Chiu, HC Lin. Esophageal Perforation: a complication of nasogastric tube placement in premature infants. J Pediatr. 2009; 154: 460-461.

27. Hysinger EB, Panitch HB. Paediatric tracheomalacia. Paediatr Respir Rev 2016;17:9-15.

28. Walner DL, Loewen MS, Kimura RE. Neonatal subglottic stenosis-incidence and trends. Laryngoscope. 2001;111: 48-51.

29. Soong WJ, Tsao PC, Lee YS, Yang CF. Therapeutic flexible airway endoscopy of small children in a tertiary referral center-11 years'experience. PLoS ONE 2017:12(8): e0183078. https://doi.org/10.1371/journal.pone.0183078

30. Hsieh KH, Choua YL, Soong WJ, Lee YS, Tsao PC. Long-term management and outcomes of tracheobronchial stent by flexible bronchoscopy in infants $<5 \mathrm{~kg}$ : A 13-year single-center experience. JCMA 2019;82:727-731.

31. Soneru CN, Hurt HF, Petersen TR, Davis DD, Braude DA, Falcon RJ. Apneic nasal oxygenation and safe apnea time during pediatric intubations by learners. Paediatr Anaesth. 2019;29:628-634. https://doi.org/10.1111/pan.13645

32. Overmann KM, Boyd SD, Zhang Y, Kerrey BT. Apneic oxygenation to prevent oxyhemoglobin desaturation during rapid sequence intubation in a pediatric emergency department. Am J Emerg Med. 2019;37:1416-1421.

End. 

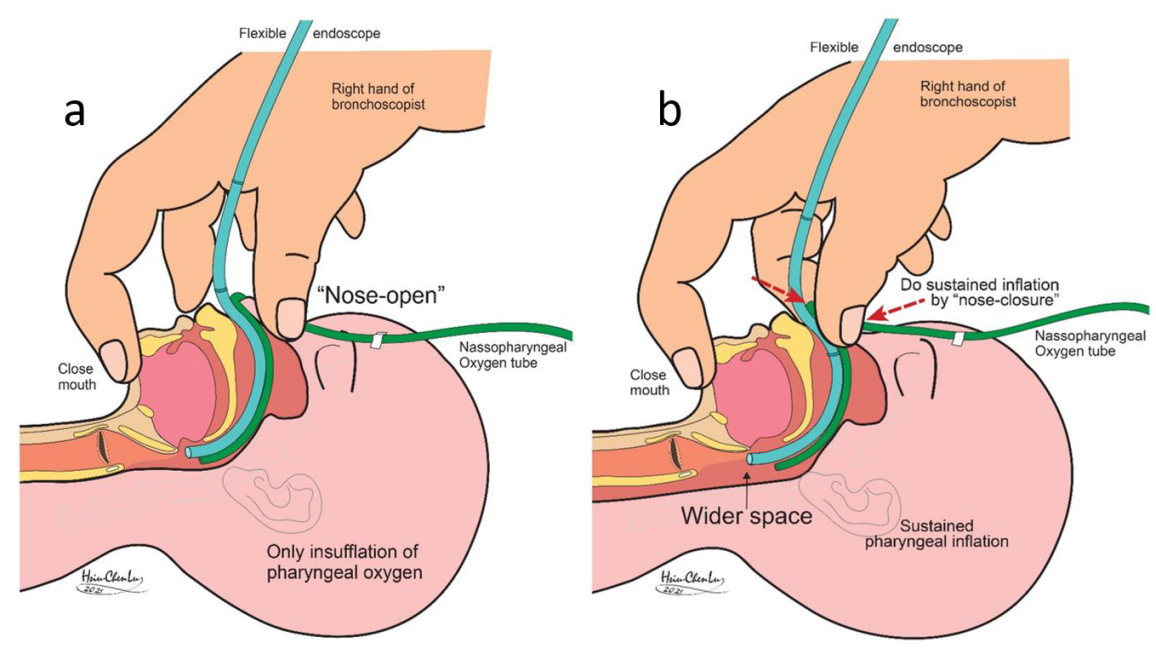

\section{Hosted file}

Table-1 Pt characters.docx available at https://authorea.com/users/370890/articles/538393flexible-endoscopy-with-noninvasive-ventilation-assesses-and-manages-infants-withsevere-bronchopulmonary-dysplasia

\section{Hosted file}

Table-2 Gross findings.docx available at https://authorea.com/users/370890/articles/538393flexible-endoscopy-with-noninvasive-ventilation-assesses-and-manages-infants-withsevere-bronchopulmonary-dysplasia

\section{Hosted file}

Table-3 Complications.docx available at https://authorea.com/users/370890/articles/538393flexible-endoscopy-with-noninvasive-ventilation-assesses-and-manages-infants-withsevere-bronchopulmonary-dysplasia

\section{Hosted file}

Table-4 Change mx.docx available at https://authorea.com/users/370890/articles/538393flexible-endoscopy-with-noninvasive-ventilation-assesses-and-manages-infants-withsevere-bronchopulmonary-dysplasia 